\title{
Picraux, Bravman, Phillips, Hays Lead Slate of 1993 MRS Officials
}

The Materials Research Society enters 1993 , its twentieth year, with nearly 11,000 members, continuing growth in its meetings and publications programs, and a new and energetic group of volunteers among its leadership.

S. Thomas Picraux, manager of the Semiconductor Physics Research Department at Sandia National Laboratories, who served in 1992 as MRS first vice president, automatically became president in 1993, succeeding G. Slade Cargill III, a research staff member of the Physical Sciences Department at the IBM T.J. Watson Research Center, who now serves as immediate past president.

Joining Picraux as newly elected members of the 1993 Executive Committee are John C. Bravman (Stanford University), first vice president and president-elect for 1994; Julia M. Phillips (AT\&T Bell Laboratories), second vice president; and A. Kay Hays (Sandia National Laboratories), treasurer. Lynn A. Boatner (Oak Ridge National Laboratory) will continue to serve on the MRS Executive Committee as secretary through the end of 1993.

In addition, six scientists representing a variety of disciplines were elected to threeyear terms on the MRSCouncil. New councillors are Bill R. Appleton (Oak Ridge NationalLaboratory), Clifton W. Draper(AT\&T Bell Laboratories Engineering Research Center), Merton C. Flemings (Massachusetts Institute of Technology), J. Murray Gibson (University of Illinois-Urbana), June D. Passaretti (Pfizer Inc. Specialty Minerals Group), and Richard W. Siegel (Argonne National Laboratory).

They join fellow councillors Aaron N. Block (Columbia University), R.P.H. Chang (Northwestern University), Russell R. Chianelli (Exxon Research and Engineering Company), Gregory C. Farrington (University of Pennsylvania), Robert Hull (AT\&T Bell Laboratories), Carol M. Jantzen (Westinghouse Savannah River Company), Paul S. Peercy (Sandia National Laboratories), Rustum Roy (Pennsylvania State University) and Carl V. Thompson (Massa- chusetts Institute of Technology). All terms became effective January 1, 1993.

A biographical sketch of newly elected president Tom Picrauxappeared in the January MRS Bulletin, p. 51. Following is biographical information on the other 1993 MRS Officers.

\section{John C. Bravman First Vice President}

John Bravman is an associate professor and associate chairman in the Department of Materials Science and Engineering at Stanford University. His research interests focus on the processing and analysis of thinfilm materials and structures. Currently, he directs doctoral students in the areas of silicon and gallium arsenide process technology, high-temperature superconductivity, the mechanical properties of thin films, and transmission electron microscopy.

After receiving his BS, MS, and PhD degrees in materials science from Stanford, Bravman worked at the Fairchild Semiconductor Research and Development Laboratories in Palo Alto, California. Healsoserved as a consultant with several Silicon Valley firms, including Lockheed, National Semiconductor, Advanced Micro Devices, and IBM. He has co-authored 70 research publications.

The recipient of numerous education awards from Stanford, Bravman has also received ASM International's Bradley Stoughton Award for Young Teachers in 1991, and the Excellence in Teaching Award from the Society of Women Engineers in 1992. He is a member of APS, ASM, EMSA, IEEE, and TMS. Bravman is a past MRS councillor, was co-chair for the MRS Spring 1990 Meeting, organized six symposia, and served on several committees. He is also a member of the Technical Editorial Board of the MRS Bulletin.

\section{Julia M. Phillips \\ Second Vice President}

Julia Phillips is supervisor of the Thin Film Research Group at AT\&T Bell Labora- tories and manager of the High $\mathrm{T}_{\mathrm{c}}$ Materials and Technology Program of the Consortium for Superconducting Electronics. Her research centers on heteroepitaxy and has concentrated on the thin-film growth of diverse materials, including high-temperature superconductors and other oxides. Phillips' other interests include epitaxial insulators and metals on semiconductors, and structural and electrical characterization of these heterostructures; ion beam analysis; and application of rapid thermal processing techniques to heteroepitaxy.

She received her BS degree in physics from the College of William and Mary and her $\mathrm{PhD}$ degree in applied physics from Yale University. She is a member of APS and Sigma $X i$. Phillips has served as MRS secretary, has been a symposium organizer, and has chaired the 1991 Fall Meeting and the following MRS committees: Program Committee, Program Development Subcommittee, Publicity and Public Relations Committee, and Corporate Participation Committee. Phillips is principal editor of the Journal of Materials Research, and member of the editorial board of Applied Physics Letters/Journal of Applied Physics.

\section{Lynn A. Boatner Secretary}

Lynn Boatner received his BS and MS degrees in physics from Texas Tech University and his PhD degree from Vanderbilt University. He was a research staff member in the Laboratory of Experimental Physics at the Ecole Polytechnique Fédérale de Lausanne in Switzerland, then joined Oak Ridge National Laboratory where he heads the Ceramics and Interfaces Section in the Solid State Division.

The author or co-author of over 200 papers, Boatner's work spans textured ceramics, rapid solidification and the physics of welding, the development and characterization of new high-durability glasses, ion implantation damage and recovery in insulating ceramics, materials synthesis and crystal growth, and high-temperature superconductors, among other areas. He holds fiveU.S. patents. A fellow of the American Physical Society and the American Association for the Advancement of Science, and a member of the Executive Committee of the American Association for Crystal Growth, Boatner has received the Jacquet-Lucas Gold Medal Award of ASM International, the 1984 DOE Materials Science Research Competition Award in Solid State Physics, and two IR-100 awards.

Boatner was a 1982 MRS Fall Meeting chair and has chaired the MRS Membership and Corporate Participation Committees. 


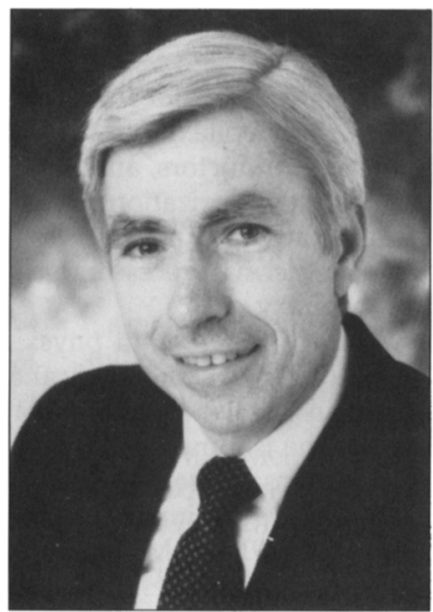

S. Thomas Picraux

\section{A. Kay Hays Treasurer}

Kay Hays is manager of Industrial Program Development in the Engineered Materials and Processes Directorate at Sandia National Laboratories. She received her MS degree in chemistry from the University of California-Berkeley and her PhD degree in physical chemistry from the University of California-Los Angeles.

Starting as a staff researcher at Sandia, Hays worked in the area of laser physics, developing high-power, ultraviolet lasers for inertial confinement fusion. Changing fields from plasma physics to plasma chemistry, she began developing radio-frequency plasma deposition techniques for a variety of applications. Later, Hays became supervisor of Sandia's Coating Research Division, where work is done in CVD, PVD, plasma deposition, thermal spray, and electrochemicaldeposition efforts. Shecurrently coordinates the laboratory's materials response to DOE's Technology Commercialization Initiative (TCI). She serves, in part, as Sandia's representative on the Materials Technical Area Coordinating Team, which is responsible for developing a strategic plan for the DOE defense laboratories materials interaction with U.S. industry and for reviewing programs funded by $\mathrm{TCI}$.

Active in both the American Vacuum Society and MRS, Hays served on the executive committee of Vacuum Metallurgy Division of AVS. She was co-organizer of the 1988 MRS Spring Symposium, Process Diagnostics: Materials, Combustion, Fusion, and was a meeting chair for the 1991 MRS Spring Meeting.

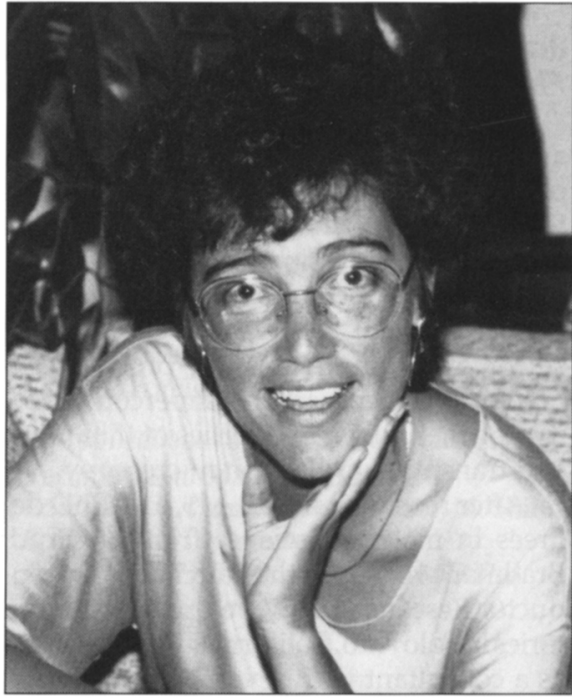

A. Kay Hays

\section{G. Slade Cargill III}

\section{Immediate Past President}

Slade Cargill graduated from Georgia Institute of Technology with a BS degree in physics and received his $\mathrm{PhD}$ degree in applied physics from Harvard University. After serving on the engineering and applied science faculty at Yale University, he joined IBM as a research staff member. He also served as senior visiting fellow at the Cavendish Laboratory and Overseas Fellow at Churchill College, Cambridge, England.

A fellow of the American Physical Society and a past general chairman of the Conference on Magnetism and Magnetic Materials, Cargill has published papers on amorphous materials magnetism, semiconduc-

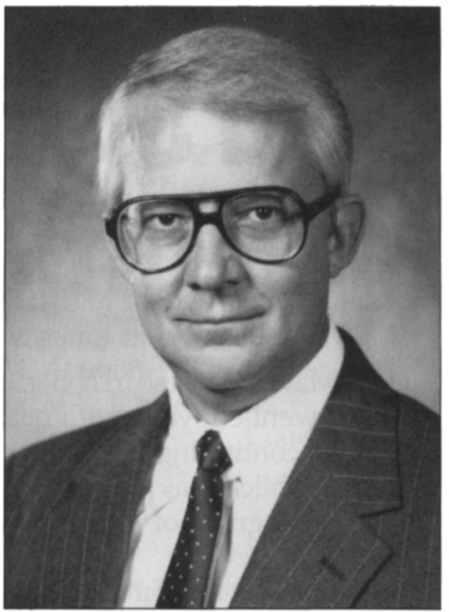

Lynn A. Boatner

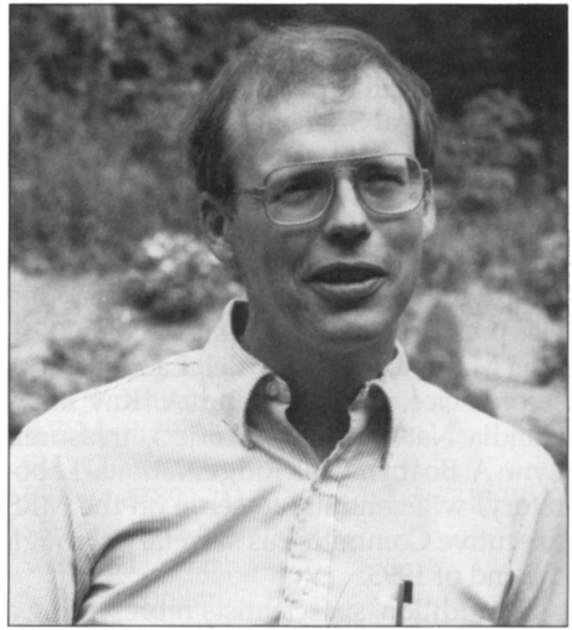

G. Slade Cargill III

tors, $\mathrm{x}$-ray scattering, and electron microscopy.

He was elected to the MRS Council in 1988 , co-chaired the 1988 MRS Fall Meeting, and was a symposium organizer for the 1985 symposium, "Phase Transitions in Condensed Systems."

His tenure on the MRS Executive Committee, as second vice president in 1990, first vice president in 1991, and president in 1992, has been marked by numerous achievements, including the expansion of MRS representation and advocacy for the materials community through the Society's external affairs, publicity, and public relations programs. 